\title{
Los viajes de Maximiliano a España y Brasil: el largo camino hacia el imperio mexicano ${ }^{1}$
}

\author{
Ingrid García-Wistädt ${ }^{2}$
}

Recibido: 19 de diciembre de 2015 / Aceptado: 3 de febrero de 2016

Resumen. En mayo de 1864 Maximiliano de Austria llega a la costa mexicana en el que será su último viaje, que culminará con su ejecución tres años después. Mucho se ha escrito sobre las razones que le impulsaron a aceptar la corona de México, un país tan alejado en todos los sentidos de su entorno cultural, sin embargo, años antes Maximiliano había viajado a España y a Brasil (a España en dos ocasiones) y estas experiencias, si no determinantes, influyeron en gran medida en la decisión del Archiduque, que vio la oportunidad de hacer realidad un sueño que se gestó en su viaje a España y se afianzó durante su estancia en Brasil, como se puede extraer de sus memorias de viaje.

Palabras clave: Literatura de viajes; interculturalidad; lugares de memoria; Maximiliano de Austria.

\section{[en] Maximilian's Journeys through Spain and Brazil: The Long Way to the Mexican Empire}

\begin{abstract}
In May of 1864, Maximilian of Austria reached the Mexican coast, being this journey his last, ending three years later with his execution. Much has been written about the reasons that prompted his acceptance of the crown of Mexico, a country so distant in every sense of his cultural environment. However, years ago Maximilian had traveled to Spain and Brazil (to Spain twice) and these experiences, although not determinant, greatly influenced the decision of the Archduke, who saw the chance to realize a dream he had conceived on his trip to Spain and that was consolidated during his stay in Brazil, as we can extract from his travel memoirs.
\end{abstract}

Keywords: Travel Literature; Interculturality; Realms of Memory; Maximilian of Austria.

Sumario. 1. Introducción. 2. El viaje a España. 3. El viaje a Brasil. 4. El viaje a la Nueva España. 5. Conclusiones.

Cómo citar: García-Wistädt, I, «Los viajes de Maximiliano a España y Brasil: el largo camino hacia el imperio mexicano», Revista de Filología Alemana 24 (2016), 35-52.

1 El presente artículo se enmarca en el proyecto de investigación del Plan Estatal del Ministerio de Economía y Competitividad FFI2013-41921-P ("Viajes y parajes. Topografias culturales de los viajeros alemanes en España").

2 Universitat de València

Email: ingrid.garcia@uv.es 


\section{Introducción}

Maximiliano de Austria, conocido sobre todo por los tres escasos años que ostentó el título de Emperador de México y que culminaron con su polémica ejecución en 1867, fue un viajero incansable. Marino apasionado, romántico y soñador, viajó por Grecia, Turquía, Italia, España, Portugal, Madeira, el norte de África, Albania, Egipto, Brasil y finalmente México. Él mismo deja constancia de sus viajes en sus memorias, editadas de forma póstuma ${ }^{3}$, y testimonio directo de su estancia en México es su correspondencia que, al igual que sus diarios de viaje, es reflejo de la compleja y polifacética naturaleza de su autor. Por un lado, hallamos al hombre de estado preocupado por cuestiones políticas, sociales y administrativas, por otro, al apasionado de la ciencia, de la naturaleza y al romántico amante del arte y de la historia. Todos estos aspectos se entremezclan en sus diarios y en su correspondencia, lo que les dota de una impronta muy particular. Aunque desde una perspectiva aristocrática y eurocéntrica, nos lega una imagen de estos países que constituye un documento único.

Para poder entender la relación de Maximiliano con América es necesario mencionar su vínculo con la hispanidad. Fernando Maximiliano José María de Habsburgo-Lorena (Viena, 1832), era hermano del Emperador Francisco José de Austria-Hungría y segundo en la línea de sucesión. Por nacimiento ostentó la dignidad de archiduque de Austria y murió en 1867 con el título de Emperador de México. La mayor parte de su bibliografía se centra en los escasos tres años de su reinado y no es descabellado pensar que podría haber pasado desapercibido para la historia de no ser por su etapa mexicana, que culminó con su polémica ejecución, inmortalizada por Manet entre los años 1867 y $1869^{4}$.

Se ha escrito mucho sobre las razones que le impulsaron a aceptar el ofrecimiento de la corona de México y no deja de resultar paradójico que un miembro de la Casa de Habsburgo-Lorena, aparentemente ajeno al mundo hispano, acabe ciñendo la corona de un país al otro lado del Atlántico, tan alejado en todos los sentidos de su entorno cultural ${ }^{5}$. Sin embargo, más de diez años antes de su llegada a México, Maximiliano había realizado tres viajes que serían decisivos a la hora de enfrentarse y aceptar el reto mexicano: dos viajes a España en los años 1851 y

3 Aus meinem Leben. Reiseskizzen, Aphorismen, Gedichte. 7 Bde. Leipzig: Duncker und Humblot 1867. Esta será la edición que se utilizará en este trabajo. Existe una versión previa de las memorias de sus viajes (ReiseSkizzen) editada de forma anónima entre 1854 y 1861; consta de seis tomos no numerados (Italien [1854], Spanien [1855], Sizilien. Lissabon. Madeira [1856], Ein Stück Albanien. Galloafrica [1856], Ueber die Linie [1861] y Bahia [1861]) que fueron reproducidos como manuscrito (así consta expresamente en la portada de cada uno de ellos: "Als Manuskript gedruckt") por la imprenta imperial de Viena (Königliche Hof- und Staatsdruckerei) con fines de uso privado.

4 El contenido político de estos cuadros no permitió su exhibición en París bajo Napoleón III, sólo el último lienzo vio la luz en vida del pintor, en Boston y en Nueva York en 1879. Sin embargo, tuvo poca repercusión y no fue hasta los comienzos del s. XX que se dio realmente a conocer < http://www.moma.org/interactives/ exhibitions/2006/Manet/> [12.11.2015].

5 Este hecho resulta especialmente singular si tenemos en cuenta que Maximiliano pudo optar a la corona de Grecia pero rehusó, porque consideraba que este país difería demasiado de los países occidentales (Ratz 2000: 22 y 2008: 11). 
1852 y uno a Brasil en el año $1860^{6}$. Los dos primeros despertaron su gusto por lo hispano (Ratz 2002: 36-39) y avivaron su nostalgia por la época de esplendor de la Casa de Austria ${ }^{7}$ y en el tercero descubrió el potencial de una terra ignota que, en su opinión, adolecía de un mal gobierno. Estos viajes le hicieron recordar con nostalgia los tiempos en los que sus antepasados gobernaban España y gran parte del Nuevo Mundo, especialmente el periodo de reinado de Carlos V, como apogeo de la Casa de Austria y como ideal de monarquía cristiana universal.

\section{El viaje a España}

Maximiliano, como se puede extraer de su diario, se considera heredero legítimo de esta estirpe que, en su opinión, aún debería estar reinando en España. Tras su visita a la tumba de los Reyes Católicos en la Catedral de Granada se expresa en los siguientes términos:

[...] es waren große Menschen, die ein Stück Geschichte gemacht, die das Ihrige auf dem weiten Erdballe geleistet, ein mächtiges weithin herrschendes Geschlecht erzeugt haben [...]. In ganz Spanien war ich den armen Todten als legitimer Verwandter der Nächste, näher als die Herrscher und Prinzen des Landes; [...] ein wehmüthiges Bedauern bewegte meine Seele, wie die großen Todten so verlassen sind, wie der neue Stamm ihrer nicht gedenkt, und wie ich in schlichter Kleidung am Sarge Jener stehe, auf deren sonnigem Throne die Unsrigen, wäre kein Carl II. gewesen, noch herrschen sollten (Maximilian 1867: 2, II: 161 y s.).

El recuerdo de sus antepasados y la convicción de que su linaje aún debería estar reinando en España despiertan la ilusión de devolverle el brillo y el poder perdidos. Maximiliano percibe que España, tras medio siglo de continuas luchas ${ }^{8}$, está en plena decadencia y compara esa situación con el momento de mayor expansión del Sacro Imperio, cuando el emperador Carlos $\mathrm{V}$ acumuló un poder político y territorial sin parangón en la historia.

6 Véase Maximilian (1867: Tomo 2 (Reiseskizzen II: Andalusien und Granada), Tomo 3 (Reiseskizzen IV: Die Balearen; Reiseskizzen V: Valencia und Murcia), Tomo 5 (Reiseskizzen X: Über die Linie), Tomo 6 (Reiseskizzen XI: Bahía) y Tomo 7 (Reiseskizzen XII: Mato Virgem)).

7 RATZ considera el viaje a España clave en la decisión de aceptar la corona de México, un país que Maximiliano ve, sobre todo, como herencia de la cultura hispánica (2000: 16); asimismo, RUDOLF defiende la idea de que España fue una de las estaciones más importantes en el viaje de Maximiliano a México (1988: 349).

8 Desde un punto de vista político, los años tras el final de la Guerra de la Independencia española se caracterizan por continuos enfrentamientos entre liberales y absolutistas. Son años de lucha contra el poder de Fernando VII: se producen varios levantamientos fallidos y tampoco cuando tras el Pronunciamiento de Riego en 1820 el rey se ve obligado a jurar por segunda vez la Constitución la situación mejora, se producen nuevos pronunciamientos y desórdenes, así como enfrentamientos entre los propios liberales. La victoria de los liberales más exaltados en las elecciones de 1822 provoca la intervención de la Santa Alianza (Prusia, Austria, Rusia y Francia) en ayuda del monarca, con cuya reposición se restaura el absolutismo. Tras su muerte en 1833 la cuestión sucesoria reanuda los conflictos, lo que conduce a una guerra abierta y al estallido de la Primera Guerra Carlista que duraría hasta 1840 y que enfrenta a los partidarios del infante Carlos con los de la futura reina Isabel II. Entre 1847 y 1849 tendría lugar una segunda y aún entre 1872 y 1876 una tercera, que terminaría con la capitulación definitiva de las tropas carlistas. Y no debemos olvidar, que dentro de este periodo de lucha constante se produce la independencia de México de España y la instauración de la república. 
Maximiliano era considerado el romántico entre sus hermanos, dotado de una gran fantasía, pintaba y escribía poesía. Se interesaba en general por la literatura y la historia, especialmente la de su familia. Los bocetos de su viaje a España, escritos en forma de diario, fueron publicados por primera vez de forma anónima en 1855. El mismo año de su muerte apareció una segunda edición, en la que debido a las circunstancias políticas fueron eliminadas o minoradas parte de las opiniones negativas y despectivas sobre otros países, especialmente Francia (Springer 1974: 20-21). Estos bocetos eran particularmente críticos con Francia, pues estaban todavía bajo la influencia de la Revolución de 1848 que culminó con la abdicación del rey y posterior proclamación de la Segunda República Francesa.

Para un monárquico convencido como Maximiliano, el hecho de que España no se hubiera visto influenciada por la Revolución Francesa había sido altamente beneficioso. Especialmente en sus bocetos se valoran de forma positiva muchas de las características que desde un punto de vista ilustrado se consideraban negativas (Jüttner 1992). Maximiliano responsabilizaba a la Ilustración de la desaparición de las viejas tradiciones populares y se quejaba de que la uniformidad francesa se hubiera extendido por toda Europa: "Glücklich das Land, wo die Romantik noch nicht ganz unter französischer Mode erstickt ist" (Maximilian 1867: 2, II: 75 y s.). Describe a los ilustrados como lobos feroces en piel de cordero, como hienas que cantan a la filantropía (Maximilian 1867: 2, II: 73), y a Francia la considera un país inmoral (Maximilian 1867: 2, II: 128). España, sin embargo, no se había visto corrompida, por lo se podían encontrar en ella huellas de una época poética y sensual (Maximilian 1867: 2, II: 48): "dort wo die alte Größe und der stolze Sinn noch nicht ganz erlöscht waren" (Maximilian 1867: 2, II: 67).

La visión que Maximiliano tiene de España se puede considerar puramente romántica y está impregnada de los estereotipos y los clichés característicos de esta leyenda que, como deja patente en su correspondencia y en su diario del viaje a Brasil, hace extensiva al Nuevo Mundo. Maximiliano no sólo admira los monumentos que le recuerdan a su propio pasado, sino también la conservación de la tradición, todo aquello que le parece natural en costumbres y divertimentos, especialmente las fiestas que desde tiempos inmemoriales, desde los tiempos de los nobles caballeros, habían sobrevivido en el que considera un siglo debilitado:

Ich liebe die Feste, in welchen sich die ursprüngliche Natur des Menschen in voller Wahrheit zeigt, mehr, als die verweichlichenden sittenlosen Unterhaltungen unserer in Luxus verschlammten Länder. Hier gehen Stiere zu Grunde, dort versinkt Geist und Seele in kraftlos sentimentalem Tand. Ich läugne es nicht, ich liebe die alte Zeit! nicht die der vergangenen Jahrzehnte, wo man im Nimbus des Haarpuders unter lau-flauen Idyllen, zwischen üppigen Wiesenblumen dem gähnenden Abgrunde entgegen kollerte; nein die Zeit unserer alten Ahnen, wo sich in Turnieren Rittersinn entwickelte [...]. Diese starke Zeit hat starke Kinder erzeugt. Was ist uns als Erbtheil von der Väter männlichen Lustbarkeiten übrig geblieben? [...] Mit welcher Sehnsucht erwartete ich die Stunde, in welcher ich eines der wenigen Feste sehen sollte, das aus der alten, ritterlichen Zeit unserem entnervten Jahrhunderte übrig geblieben (Maximilian 1867: 2, II: 70-78). 
Hay que tener en cuenta que a pesar del interés creciente de siglos anteriores, en la primera mitad del siglo XIX España era aún un país desconocido, de lo que dejan constancia la mayoría de los viajeros de la época (García-Wistädt 2009, 2011) ${ }^{9}$. La imagen de España que impregnaba gran parte del imaginario alemán estaba fuertemente influida por la literatura y por una visión orientalista de ese país. Recordemos que en el s. XIX el Orientalismo en Europa vivió un momento álgido, y el concepto 'Oriente' en ese periodo incluía la España árabe, como puente entre la cultura islámica y Occidente. Este interés estaba condicionado, en gran parte, por la contraposición histórica de Oriente y Occidente, se trata del entusiasmo de Herder por la España musulmana como cuna de una nueva cultura; de Oriente como la patria de la humanidad $^{10}$. La atracción por España oscilaba entre la fascinación y el rechazo lo que derivó en una imagen del país ambivalente, positiva y romántica, por un lado, y deformada y negativa, por otro, pues aún persistía la imagen promovida sobre todo por los franceses que veía en España la antítesis de las aspiraciones de la Ilustración (Wolfzettel 2003).

A Maximiliano le fascinan de forma especial los lugares donde precisamente se aúnan Oriente y Occidente, como es el caso del Alcázar de Sevilla, donde se une la digna seriedad gótica creada por el espíritu germánico cristiano con la ornamentación poética de Oriente: "Mit kunstvollem Geschicke sind die ernsten, würdevollen Linien des gothischen Styls mit der Fülle und dem poetischen Schmucke des Morgenlandes vereinigt" (Maximilian 1867: 2, II: 41). En ningún otro país donde florece el arte ha visto nada similar. Para Maximiliano el arte islámico es la obra de un pueblo creyente que no ha sido iluminado por la luz verdadera, y una vez más remite a quien supo respetar las virtudes de la sabiduría de los árabes:

Carl's V. poetischer Geist wußte noch die weiten Räume, welche des heiligen Ferdinand's Schwert dem Prophetenstamme entrissen hatte, zu ehren. Doch Spaniens weiche Luft erschlaffte der Deutschen und der Franken Herrscherstämme, und mit ihnen erstarben die großen Gedanken und ihre Schöpfungen (Maximilian 1867: 2, II: 45).

Sin embargo, esta admiración por la figura de su antepasado no la despierta sólo su viaje a España. Ya con anterioridad, en su visita a la Galeria Uffizi en Florencia, mostró su fascinación ante la contemplación del retrato ecuestre de Carlos $\mathrm{V}$ de Van Dyck:

Aunque cronológicamente los viajes de Maximiliano pertenecen a la segunda mitad del s. XIX, su imagen de España se corresponde más con la de los viajeros de la primera mitad del siglo, sobre todo a partir de las Guerras Napoleónicas.

10 "Spanien war die glückliche Gegend, wo für Europa der erste Funke einer wiederkommenden Cultur schlug, die sich denn auch nach dem Ort und der Zeit gestalten mußte, in denen sie auflebte. Die Geschichte davon lautet wie ein angenehmes Mährchen. [...] Die Erscheinung selbst, daß an den Grenzen des Arabischen Gebiets sowohl in Spanien als in Sicilien für ganz Europa die erste Aufklärung begann, ist merkwürdig und auch für einen großen Theil ihrer Folgen entscheidend" (Herder 1821: 273, 279). Ya no se trata sólo de la imagen cruel del musulmán de las cruzadas medievales o de las guerras turcas de la Edad Moderna, tampoco de la visión paternalista de superioridad que según Said (1990: 245) caracteriza el interés por el Oriente de finales del s. XIX y principios del XX (García-Wistädt 2012). 
Will man den großen Kaiser und seine Thaten begreifen, will man den stolzen Erdensohn kennen lernen, in dessen Besitzthum die Sonne nie sank, der das plus ultra über den Ocean donnerte [...], so trete man vor dieses Bild, und ein Schauer der Ehrfurcht und Begeisterung wird unser Inneres vor des Herrschers Majestät ergreifen. [...]. Daß van Dyk [...] Geschichte gemalt hat, indem er der großen Männer unsterblichen Geist in seinen ernsten Farben verewigte, zeigte er am vollendetsten in diesem Bilde der am schwersten zu lösenden Aufgabe seiner Zeit; denn schwer ist's denjenigen zu malen, der sich als den Ersten in der Welt fühlt, der außer seinem Schöpfer Niemanden über sich anerkennt; der es mit ungebeugten Stolze wagt, den Papst in seiner Engelsburg zu belagern, Frankreichs König unter seine Gefangenen zählt, und des Geheimnisses inne wird, daß es nicht gut sei, auf dem sonnenumwallten Throne die Dämmerung abzuwarten, um den Tod der Sterblichen zu sterben (Maximilian 1867: 1, I: 258 y s.).

Y en su posterior viaje a Valencia, durante su visita a la Audiencia ${ }^{11}$ queda especialmente maravillado por los frescos en la sala de sesiones que mostraban las Cortes bajo Carlos V: "wie sie leibten und lebten, in ernster Würde nach Rang und Geburt sitzend, Adel, Geistlichkeit und Städte, alle Schiller's Worte bestätigend: 'Stolz will ich den Spanier'" (Maximilian 1867: 3, V: 100). Esta sala es para Maximiliano una de esas raras antigüedades que nos hacen retroceder en el tiempo:

Dieser Saal mit seinem Grandenstolz ist eines jener seltenen Alterthümer, welches uns plötzlich um einige Jahrhunderte zurückversetzt, und nicht in eine Gesellschaft von Vermodernden, sondern in das ernste weise Leben der goldenen Zeit des goldenen Reiches; durch seine treffliche Erhaltung wird das Kunstwerk zu einer geschichtlichen Vision [...] (Maximilian 1867: 3, V: 101).

En las visiones de Maximiliano se aúna el interés por el pasado desde una perspectiva política, religiosa y artístico-estética. $\mathrm{Su}$ particular Edad de Oro. En la misma línea considera la Lonja de Valencia como: "das bemerkenswerthe architektonische Denkmal einer Zeit, wo noch Harmonie und Aesthetik dem menschlichen Auge und Herzen ein Bedürfniß waren, was man von unserem magern, dürren Jahrhundert leider nicht sagen kann" (Maximilian 1867: 3, V: 101). Son también reminiscencias de una cristiandad antigua, de la sencillez y la grandeza que se inclinan ante la señal de la cruz.

El sueño de Maximiliano descansa sobre la contemplación nostálgica de monumentos, que funcionan como una crónica que enlaza el presente con el pasado. El Habsburgo percibe la estela de la historia gloriosa de España que se contrapone a un presente decadente y corrompido, como es el caso ante el majestuoso "palacio" que alberga el Ayuntamiento de Sevilla:

Schon aus diesem Gebäude blicken mir Familien-Erinnerungen entgegen. Erinnerungen an eine Zeit, in welcher Spanien [...] auf dem höchsten Gipfel der Macht und das größte Reich der Welt war, Zeiten, in welchen ein mächtiger

11 Palacio proveniente de la Edad Media donde se reunían las Cortes; actualmente, Palacio de la Generalitat. 
Habsburger das kühne plus ultra rief, und durch die Säulen des Hercules eine Bahn der Zukunft brach [...] (Maximilian 1867: 2, II: 24),

en una clara referencia al descubrimiento de América. Todos los edificios que contempla y admira son para él recuerdos de tiempos mejores para la pobre España (Maximilian 1867: 2, II: 81), un país en el que poco queda de su época gloriosa, echada a perder bajo la desidia del reinado de la estirpe, degenerada y decadente, de los Borbones: “denn in der Langeweile geht alles, wie im todten Meere, zu Grunde; das Leben erstirbt und mit ihm die That, wie es uns leider die Geschichte Spaniens, dieses armen schönen Landes zeigt" (Maximilian 1867: 2, II: 187). Y en los siguientes párrafos, eliminados de la edición de $1867^{12}$, deja muy clara su opinión sobre la situación política del país así como sobre su propia postura política, abiertamente monárquica y anticonstitucional:

[...] la corte de Madrid está entregada a continuos placeres y licencias y el infeliz país pone de manifiesto cómo se llevan los asuntos de estado. ¡Qué lástima para esta dorada península, el más bello reino de Europa! Bajo manos fuertes y sabias podría ser uno de los más florecientes y poderosos, pero los Borbones se han perpetuado y allí donde gobiernan, los reinos y la historia van cuesta abajo [...], la tierra está hundida porque sus soberanos están hundidos: Sólo podría resurgir de nuevo si hubiera una mano que le ayudara. ¡Qué nuevos caminos podrían construirse, cuántas fuentes de riqueza podrían abrirse, cuántas relaciones comerciales establecerse! [...] Pero todo esto son pia desideria, pues para el suelo tórrido y meridional de España su constitución es como el escorbuto que todo lo reduce a podredumbre [...], es sólo la cobertura para el cómodo relleno de los sacos privados de la bolsa grande y perforada del estado. ¡Pobre, bello y querido país! Tendrías que tener un Francisco José o una María Teresa que te enseñara que también una mujer puede prestar grandes y gloriosos servicios (Maximiliano 1999: 165 y s.).

Esta última referencia es una clara alusión a la reina Isabel II. De forma similar se expresará un año más tarde en su segundo viaje a España en un fragmento que también fue eliminado de la edición de 1867 en el que Maximiliano, tras la contemplación en la Audiencia de Valencia de los "grandes soberanos [que] han regido el mundo, con la palabra y con la espada [...] y que han impreso su sello a una nueva parte del mundo", le desea a su querida España un Francisco José:

Por desgracia actualmente falta en España, estado monárquico por los cuatro costados, una cosa que lo es todo: los grandes soberanos. Éstos se han convertido en el juguete de las intrigas de sus camarillas. Éstas están ahora compuestas por los ministros constitucionales que, en un amor patrio de nuevo cuño, sólo han fijado una meta a sus esfuerzos: el dinero. De esta manera se tambalea la bella y pobre

12 Como ya se ha mencionado con anterioridad, en la edición de 1867 se evitaron opiniones ofensivas o críticas contra ciertas naciones, lo que explicaría por qué se eliminó esta alusión a la incapacidad de los gobernantes españoles (Springer 1974: 20-21). Al no haber tenido acceso al documento original, todas las citas de esta edición se han extraído de la traducción de Karl Rudolf y Miguel Ángel Vega (1999), que toma como base el volumen Reise-Skizzen. Spanien de 1855. 
España sobre las olas de esos intentos salvadores del pueblo, o mejor dicho, exprimidores del pueblo. Necesita que venga una mano, de hombre o de mujer, que con energía e inteligencia tome el timón, estudie la brújula y entonces, en la dirección que haya elegido, se dirija imperturbable hacia un mejor y sólido futuro. [...] Que [España] hoy está en el camino erróneo lo percibirá cualquiera que haya visto y estudiado la crisis del siglo XIX. [...] ¡Quiera Dios darte, pobre y querida España, un Francisco José! (Maximiliano 1999: 216).

Y ante esta situación se permite en ocasiones soñar con lo bonito que sería poder reinar en España, el país de los sueños dorados y la dulce nostalgia (Maximilian 1867: 2, II: 221), como es el caso ante la tumba de los Reyes Católicos, mientras contempla y sostiene en la mano su corona y su espada: "Ein schöner glänzender Traum wäre es für den Neffen der spanischen Habsburger, letzteres zu schwingen, um ersteres zu erringen" (Maximilian 1867: 2, II: 164).

\section{El viaje a Brasil}

Fue el interés de Maximiliano por la historia, por el arte y por las ciencias naturales, especialmente la botánica, aunque también la decepción de ver truncadas sus ambiciones políticas en Europa, lo que le había llevado en los años 50 a recorrer casi todos los países mediterráneos e Inglaterra. Sin embargo, en su visita a Brasil al final de la década y su incursión en la selva amazónica se pueden percibir ya ciertos rasgos de escapismo. Tras la pérdida en 1859 de las posesiones austriacas en Lombardía y Venecia y el consecuente fracaso de su virreinato, que supone también un debilitamiento de la monarquía de los Habsburgo, Maximiliano se retira de la vida pública y cobra fuerza la idea de que sólo fuera de las fronteras de Europa, donde el ser humano aún no ha dominado y explotado la naturaleza puede ver satisfechas sus ansias vitales (Burian 1990: 508), que tras su aceptación de la corona de México se convertirán también en políticas.

Anhelando, pues, seguir las huellas de sus antepasados y hastiado de la situación política en Europa, en diciembre de 1859 partió en la fragata de guerra Elisabeth hacia Brasil, única monarquía independiente en América. Con este viaje, cuya finalidad era fundamentalmente científica, quería, además, realizar una visita oficial al emperador Pedro II, con quien estaba emparentado ${ }^{13}$ y consolidar las relaciones con Austria ${ }^{14}$. Cuando avistan tierra el 10 de enero de 1860 , con el mismo tono emotivo y nostálgico que caracteriza sus bocetos sobre España, rememora una vez más la historia, que es la historia de su familia, y se ve a sí mismo predestinado

13 Pedro II era hijo del emperador Pedro I (quien había proclamado la independencia de Brasil) y la Emperatriz consorte María Leopoldina de Austria (tía de Maximiliano) y hermano de María Amelia de Braganza (hija de Pedro I y su segunda esposa, Amelia de Beauharnais) con quien el joven archiduque se había prometido en 1852, un matrimonio frustrado debido a la muerte de la princesa por tuberculosis un año después.

14 La expedición de Maximiliano se diferencia de las de otros viajeros por su carácter mixto, por su doble naturaleza, algo poco habitual en las expediciones de la época, que por regla general solían tener una metas muy claras: militares y políticas o, en menor medida y de forma más bien independiente, científicas. Que se enviara una fragata de guerra, como ya ocurriera en viajes anteriores de Maximiliano o en la vuelta al mundo de la fragata Novara, con tareas combinadas políticas y científicas causó una gran impresión en Europa y existen testimonios de que este pluralismo de motivos fue muy admirado en el extranjero (Hamann 1992: 123, 126 y s.). 
a ser el primer heredero de sangre de los Reyes Católicos llamado a pisar el nuevo continente: "Ein Mährchen scheint es mir, daß ich der erste Blutserbe Ferdinands und Isabellens bin, dem es von Kindheit an eine Lebensaufgabe war, einen Continent zu betreten der für die Geschichte der Menschheit eine so riesenhafte Bedeutung erlangt hat" (Maximilian 1867: 5, X: 216).

Este era el primer viaje a América de un archiduque y a lo largo de toda la travesía encontramos manifestaciones de orgullo y satisfacción. Maximiliano tiene la sensación de que es el comienzo de algo grande: "Solche unschuldigen Triumphe fügen sich besser in mein Trachten und Streben als was mir die Heimat Prunkhaftes bieten kann; ich war der erste meines Stammes, der bis an die Tropen wanderte, und zwar mit dem Gefühle, daß ich noch nicht am Ziele sei” (Maximilian 1867: 5, X: 185), escribe el 28 de diciembre de 1859. Cuando el 7 de enero atraviesan el Ecuador lo percibe como un triunfo personal: “"Elisabeth' ist der erste österreichische Dampfer, der, seit Dampf die Welt regiert, die Linie passirt hat, und wenn auch eine Frau meines Stammes uns den Weg in die neue Welt gezeigt hat, so freue ich mich doch, der erste Mann meines Hauses zu sein, der in die südliche Hemisphäre einzieht" (Maximilian 1867: 5, X: 213).

Durante la travesía profundizó en la lectura de otros relatos sobre Latinoamérica que había encontrado en la biblioteca de la corte en Viena (Hamann 1992: 124) y cuando al fin la costa de Brasil aparece ante sus ojos, el joven Maximiliano siente una excitación febril, se encontraba a las puertas del paraíso: "war doch heute der Tag, wo der jahrelange Traum, Amerika's Boden zu betreten, verwirklicht werden sollte" (Maximilian 1867: 6, XI: 14). La impresión y la emoción que le produce su llegada a Bahía, equiparable a la que experimentó al alcanzar las costas españolas, le sobrecoge con la fuerza de un torrente; se le muestra en todo su esplendor un mundo de sensaciones completamente nuevo, de una variedad y un exotismo que incluso sobrepasan su imaginación y sus expectativas. Absorbe todas las impresiones con el entusiasmo del romántico y describe con un extremado lirismo las primeras impresiones de este imponente país:

Unter reicher goldener Sonnenfülle und glänzend blauem Himmel fuhren wir mit freudig gehobenem Gemüthe gegen $10 \mathrm{Uhr}$ in die große weite Bahía de todos os Santos ein. Es war einer jener glücklichen Augenblicke, wo sich dem Menschen im vollsten Sinne des Wortes eine neue Welt aufthut [...], wo die Natur mit ihrem regellosen Luxus allein herrscht, wo nichts aus Menschenhand Geschaffenes, nichts Abgeschlossenes, des Wanderers Aufmerksamkeit auf sich zieht [...] (Maximilian 1867: 6, XI: 3).

Sus observaciones muestran la mirada del europeo consciente de las limitaciones de esta perspectiva y de la imposibilidad de una descripción fiel. Henchido de orgullo y humildad científica a un tiempo, no se siente capaz de expresar sus sensaciones:

Meine Stimmung in Worte zu fassen ist unmöglich; es war eine jener glücklichen im Menschenleben so seltenen Tage, wo sich das enthusiastische Gefühl des Triumphes, das sichere Erfassen des Schwererreichten mit der unnennbaren Wonne des Erforschens und Anschauens einer neuen, ganzen Welt verbindet. 
Mein Geist und meine Sinne waren geschärft, um mit jener höheren Thätigkeit des Glückes alles Neue, Wunderbare aufzunehmen, was ich bis jetzt nur aus Buch und Phantasie kannte. Mein Herz schlug in [...] dem süßen Zweifel, ob die Uebertragung in die Wirklichkeit dem in mir getragenen Ideale entsprechen, oder dasselbe gar übertreffen würde. Für einen Naturfreund und leidenschaftlichen Reisenden wie ich, ist es ein unvergeßliches Moment in jene Welt zu treten, wo das Erlernte zum Erlebten wird, wo die mühseligen und beschränkten Sammlungen unseres kalten Europa's in Fleisch und Blut vor und um uns stehen und unsere engen Glashäuser mit ihren Pigmäen-Exemplaren sich zu Wäldern und riesigen Formen ausdehnen (Maximilian 1867: 6, XI: 15-16).

Desde Río de Janeiro Maximiliano se dirige a la zona más recóndita de Brasil, a la selva amazónica, en la que se interna junto al almirante Wilhelm von Tegetthoff y en la que permanece varias semanas. Esta inmersión en lo desconocido la percibe como una nueva conquista, la selva brasileña está aún por descubrir y para un europeo es imposible de imaginar, es la viva imagen del edén: la "república libre de las plantas". Intentar describirla es un vano delirio:

[...] kein Autor hat es beherzt versucht, keinem ist es gelungen. [...] er kann die Farben des Bauwerkes angeben, er kann erzählen wer darin wohnt [...], aber weder die Photographie des brasilianischen Waldes [...] noch die Beschreibung kann dem Fremden ein irgend genügendes Bild zeigen; es fehlt für beide der Maßstab, der Anknüpfungspunkt an die Heimat. Wer einen Begriff davon haben will, dem bleibt nichts übrig als aufzupacken und selbst hinzureisen (Maximilian 1867: 6, XI: 66-67).

Esta experiencia la percibió como existencial, al depender el hombre únicamente de sus fuerzas y su voluntad. Se trataba de un mundo de inseguridad, de aventura, de lo ominoso e impredecible, una experiencia vital que le marcaría de forma psicológica el resto de su vida (Hamann 1992: 125-126). A las puertas de la selva virgen no alcanzaba la civilización y a medida que la expedición se adentraba en el interior del país empezaba un mundo completamente nuevo e ignoto.

$\mathrm{Su}$ viaje a Brasil fue una expedición botánica largo tiempo anhelada. Con la experiencia que había adquirido en anteriores viajes y, sobre todo, en la organización de la Expedición Novara (1857-1858), para la que había pedido "instrucciones" a Alexander von Humboldt (Scholler 1958), Maximiliano viaja en compañía de eruditos, artistas, pintores, botánicos, jardineros, médicos, cazadores... (Maximilian 1867: 6, XI: 128-129), que tenían la misión de describir, dibujar, recoger muestras para las ricas colecciones austriacas, lo que requería una gran capacidad organizativa ${ }^{15}$ :

15 Las plantas no eran sólo descritas y catalogadas sino que en la medida de lo posible eran llevadas o enviadas a Europa y muchas nuevas plantas exóticas se pudieron contemplar y admirar en los jardines del Castillo de Schönbrunn, Miramar o Lacroma. Asimismo, animales de pequeño tamaño fueron enviados al zoo imperial en Viena. Acompañó también a Maximiliano el pintor y paisajista Joseph Selleny y hubo incluso intentos fotográficos, pero no podían competir con el elaborado arte del pintor (Hamann 1992: 125). El cirujano a bordo y botánico Heinrich Wawra von Fernsee publicaría, en colaboración con Franz Paula Maly, botánico y jardinero real en Schönbrunn, los resultados de sus investigaciones en 1866 bajo el título Botanische Ergebnisse der Reise Seiner Majestät des Kaisers von Mexico Maximilian I. nach Brasilien (1859-1860). 
[...] der Botaniker bereitete Schachteln, Büchsen und Körbe, packte Fließpapier zum Trocknen [...]; der Waidmann ordnete seine Gewehre [...]. Der Maler spitzte seine vielfarbigen Stifte, ordnete seine Zeichenbücher [...]; der Doctor putzte an seiner Lanzette, [...] steckte, auf den Schlangenbiß bedacht, allerhand Gegengifte in seine Taschen [...], um uns, so weit es in seiner Kraft stand, wieder lebend aus dem Mato Virgem heimzusuchen (Maximilian 1867: 7, XII: 16).

Maximiliano, amante e impulsor de las ciencias naturales, era considerado en los círculos eruditos un experto conocedor en cuestiones de ciencia. Ya desde su infancia tuvo una especial inclinación por lo "tropical" (Hamann 1992) y en este viaje rememora con frecuencia sus impresiones de juventud. Maximiliano, el pesimista cultural, encuentra en Brasil esa tierra no corrompida por la cultura; por ejemplo, contrapone de forma metafórica el cocotero brasileño y su libre albedrío a la proporción de la datilera de occidente: "die Kokospalme, der typische Baum der echten tropischen Welt, im Vergleich zur Dattelpalme - das Bild des Ebenmaßes und das Prototyp, nach dem sich Aegyptens ernste und Griechenlandes warme Kunst gebildet -, das unregelmäßige Bild der culturlosen Erdhälfte” (Maximilian 1867: 6, XI: 19).

Sin embargo, en su visita a una plantación de azúcar se abre por primera vez una brecha disonante en un diario que, por lo general, se caracteriza por la exaltación romántica: la práctica de la esclavitud. Es especialmente crítico con los representantes de la Iglesia que lo permiten e incluso lo fomentan y se benefician de ello. Sin embargo, aunque rechaza la esclavitud y habla de libertad, no así de igualdad ${ }^{16}$. Asimismo, es incapaz de aceptar y de entender la imbricación de rituales paganos con la liturgia católica tan característicos del país y sin las que el clero sudamericano parece no poder sostenerse; lo considera repugnante y describe la escena que contempla como un aquelarre negro. Llega a la conclusión de que en Brasil no existe un verdadero catolicismo, una afirmación que hará extensiva a México. Fiel a la política josefista del imperio austriaco, consideraba que el Estado debía tener el control sobre la Iglesia (Galeana 1991: 46) ${ }^{17}$.

Maximiliano critica a un gobierno que no gobierna y permite el enriquecimiento mediante la trata de carne humana; a un imperio que califica de pobre, débil, sin poder ejecutivo, sin fondos... Considera que los gobernantes viven en el frenesí de la auto-sobreestimación y que la libertad en Brasil encierra en sí misma el mayor despotismo: "Die constitutionellen, plappernden Oligarchen verstehen die Freiheit

16 Con frecuencia resalta la semejanza de los negros con los monos, y no sólo por su fisonomía: "höheren Seelenausdruck sucht man in dem dunklen Spiegel umsonst, die Kinder der Schwarzen, wie niedliches Spielzeig, erinnern aber in ihren Bewegungen an den Urwald und die Kokosnüsse; scheußlich sind dagegen die Alten, es fehlt ihnen das Ehrwürdige, die Schönheit des Alters, und sie erinnern mich unwillkürlich an jenen greisen, schneeweiß gewordenen Affen, den ich im Jardin des plantes trauern sah. Kindheit und Alter mahnen bei den Schwarzen an das Thier; nur in der Jugend und in der Fülle der Kraft scheinen sie sich vorübergehend zum Menschen emporzuraffen" (Maximilian 1867: 6, XI: 36).

17 Sin embargo, siguiendo a Ratz (2008: 6), lo religioso no era predominante en su pensamiento, sino un ritual obligado: "Religion aus Pflicht ist nothwendig, tröstend und hält allein den Menschen im Gleichgewichte, Religion aus Passion ist eine Leidenschaft wie eine andere, artet gewöhnlich in Fanatismus aus, quält und peinigt seine Opfer, schlägt aber auch gar oft in das gerade Gegentheil um" (Aphorismen, 17. Juni 1860), (Maximilian 1867: 7, XII: 205). Siguiendo a CORTI (1997: 35), el primer biógrafo de Maximiliano, aunque la religión formó parte de su educación, el conde Enrique Bombelles, bajo cuyo cuidado estuvo su formación, "cuidaba de que no se le imbuyese a los niños una devoción beata y santurrona, extraña a la esencia del cristianismo, que nada tiene que ver con la verdadera fe". 
darin, ihre Sclaverei vor jedem Neuerungsangriffe zu schützen und der Regierung, das heißt dem Wohle des Staats keine Steuer zu zahlen" (Maximilian 1867: 6, XI: 102-103). También el odio de los brasileños a los jesuitas habría frenado el desarrollo del país; Maximiliano pone en duda que precisamente este pueblo se haya beneficiado de su expulsión y critica el sometimiento del gobierno brasileño al intolerante Reino de Portugal: "Hätte die [brasilianische] Regierung die schwierige Kunst verstanden sich über die Jesuiten zu stellen, und ihre Zähigkeit und Feinheit, ihren wissenschaftlichen Geist zur Ausbreitung der Cultur zu benutzen, so wäre die jetzt bestehende Verwilderung vielleicht nicht eingetreten" (Maximilian 1867: 6, XI: 121).

A pesar de todo, Maximiliano sigue respirando y disfrutando el aroma de la libertad, se entusiasma por los ataques de los indios, que describe con tal realismo que inspiró incluso a Karl May, como relata Brigitte Hamann (1983: 35) ${ }^{18}$. Sin embargo, para el joven archiduque la libertad en este país tiene también rasgos negativos: en Brasil, al contrario que en Europa, la casa, el hogar no es el centro alrededor del que gira la vida de su propietario, sólo es, de forma alterna, sombrilla o paraguas, y para la noche una cama con dosel donde airear la ropa sin ser molestado y poder disfrutar de la brisa (Maximilian 1867: 6, XI: 79). Y como la casa no puede albergar recuerdos ni tiene historia, es la maldición del habitante del trópico, condenado a la fragilidad o incluso ausencia de la vida familiar y las relaciones sociales: "es gibt dem Charakter das Unstäte, das Wechselnde, neben dem der Begriff der Familie nicht aufkommt; denn wie die Grundlage nur vorübergehend ist, so ist auch das Band der Familie nur für den Augenblick geknüpft, es wird gezeugt und geboren, und sonst so ziemlich dem Gethiere im Urwalde gleich gelebt" (Maximilian 1867: 6, XI: 80).

Cuatro son los motores, según Maximiliano, que destruyen la sociedad en Brasil: en primer lugar, la falta de una estirpe fuerte y unificadora en la que las generaciones sobrevivan con las mismas costumbres y naturaleza; en segundo lugar, la inexistencia del concepto y el sentimiento de conciencia, provocada por un clima invariable y el hastío de naturaleza. De este segundo punto se deriva de forma evidente el tercero, la falta total de una base religiosa que aspire a algo más elevado que la simple naturaleza porque, desgraciadamente, la naturaleza sólo es hermosa; por último, la atroz esclavitud, que considera la maldición y la perdición de Brasil (Maximilian 1867: 6, XI: 102) y que aúna las tres lacras anteriores a la vez que las vuelve a engendrar (Maximilian 1867: 6, XI: 80-81). Por tanto, la obligación de cualquier hombre honrado, independientemente de su estatus y su nación de procedencia, es combatir la esclavitud, con la palabra y los hechos.

Todos estos aspectos negativos, estas carencias, y la incompetencia de la administración le hacen reafirmarse en su idea de que Brasil necesita un gobierno fuerte que sepa aprovechar y sacar el máximo partido a todo el potencial que ofrece. Y quién mejor que un Habsburgo para lograrlo. Siguiendo a Kahle (1992: 88-89), ya

18

También otros viajeros como Oscar Canstatt utilizan a Maximiliano como fuente, colocándole al mismo nivel que científicos de la talla del naturalista suizo Johann Jakob von Tschudi y del botánico y etnógrafo Carl Friedrich Philipp von Martius: "Wenn ich daher im Folgenden den Leser einlade, mich auf einer Reise in das Innere zu begleiten, so bemerke ich dazu, dass ich an jenen Orten, welche zu besuchen mir selbst nicht gesta ttet war, namhaften als Brasilienkenner bekannten Forschern wie v. Tschudi, Martius, Erzherzog Maximilian und anderen das Wort überlassen werde" (Canstatt 1912: 254). 
en este viaje Maximiliano concibió la idea de una relación dinástica entre Austria y Brasil, que tras su aceptación de la corona mexicana se convertiría en el proyecto de una doble monarquía. En México maduró la idea de expandir su imperio y crear un imperio americano de los Habsburgo, desde Río Grande en el Norte hasta Río de la Plata en Argentina: un doble imperio México-Brasil. Dos Habsburgos reinando en América que se apoyaran mutuamente reforzaría el sentido monárquico y atraería y podría incorporar a otras pequeñas repúblicas. Sin embargo, el primer paso habría sido que su hermano menor, Ludwig Viktor, hubiera estado dispuesto a casarse con la heredera de la corona de Brasil (más adelante él lo habría nombrado heredero de la de México), sin embargo, su hermano no iba a acceder voluntariamente (Hamann 1983: 43-44) y tampoco Francisco José, en su calidad de emperador, mostró interés alguno ni estuvo, como le había pedido Maximiliano, dispuesto a ordenárselo.

\section{El viaje a la Nueva España}

Como dejó patente en su viaje por España, la relación de Maximiliano con la historia se mueve dentro de los parámetros del Romanticismo y su particular relación con el pasado, en el que cree encontrar vigentes todos los valores que echa en falta en su tiempo. Es la tradición romántica de la mirada a la propia historia y su proyección al futuro. En el caso concreto que nos ocupa, la época de esplendor de la Casa de Austria significaba para Maximiliano su propio pasado, que identificaba con un estado ideal, y la contemplación y percepción de los lugares de memoria histórica era análoga a la que los románticos percibían en la contemplación de la literatura, de la pintura, del arte medieval en general. No es por lo tanto disparatado pensar que le invadiera el mismo sentimiento ante la posibilidad de continuar la labor de sus antepasados en México, cuya historia estaba tan estrechamente ligada a la de España y a la de su familia y que se considerara misionario de esos grandes hombres de espíritu poderoso que en el pasado regalaran la cuna del futuro al género humano (Maximilian 1867: 5, X: 216) ${ }^{19}$. Además, la inestabilidad política del antiguo virreinato no distaba mucho de la de España:

19 El hecho de que Maximiliano fuera un Habsburgo descendiente del emperador Carlos V, entre cuyos dominios había figurado Nueva España, tampoco pasó desapercibido a los monárquicos mexicanos que vieron en él un candidato idóneo: "El nombre del archiduque Maximiliano se presentaba naturalmente en esta coyuntura" (Arrangoiz 1869: 27). En el siguiente dictamen de la Junta de Notables se puede observar la admiración que sentían por Maximiliano más allá de sus dotes de gobernante: “Oh, no, señores; nadie hay en México hoy que no conozca históricamente al esclarecido personaje [...] cuyas altas prendas y relevantes virtudes tiempo ha que han atravesado el Atlántico sobre las alas de la fama. Vástago excelso del insigne linaje de la casa de Austria, una de las más antiguas dinastías de Europa, y hermano de S. M. el Emperador reinante Francisco José, desde su primera juventud se consagró a cultivar en su espíritu aquellos conocimientos que debían hacerlo digno de los supremos destinos a que estaba llamado. [...] La Grecia, la Italia, la España, el Portugal, Tánger y la Argelia, el litoral de la Albania y la Dalmacia, las costas de la Palestina, el Egipto, Suecia y la Sicilia, la Alemania septentrional, Bélgica y Holanda, Lombardía e Inglaterra, las Islas Canarias y Madeira, y por última el Imperio del Brasil, fueron sucesivamente el objeto de sus más profundas observaciones, enriqueciendo más y más el ya abundante depósito de su memoria, las fuentes de su ardorosa imaginación y el caudal extraordinario de sus conocimientos. [...] Dotado de una disposición natural para las artes, las ciencias y las letras, las cultiva, con ardor y lucimiento" (Dictamen. Presentado por la Comisión especial de la Asamblea de Notables en la sesión del 8 de Julio de 1863, sobre la forma de gobierno que conviene adoptar en México. Boletín de las leyes del Imperio Mexicano I, 1863: 501-538, aquí 533, 537). 
Hacía años que México no presenciaba más que luchas sangrientas y guerras fratricidas. Los golpes de Estado, los cuartelazos, las asonadas militares, los asaltos al poder; los pronunciamientos y revoluciones; el fuego, la sangre, los saqueos; la anarquía y el desorden eran lo habitual en aquel México anterior a 1864 que tenía más de cincuenta años de debatirse impotente (Elizondo 1956: 62).

Esta predisposición natural, el convencimiento de estar llamado a continuar la labor de sus antepasados, la creencia sincera en una mayoría monárquica en Méxi$\mathrm{co}^{20}$, unidos a la férrea voluntad de su esposa y a la imposibilidad de satisfacer su vocación en el plano político europeo, hacen que Maximiliano, que había sido educado para gobernar, a pesar de las aprehensiones, de las vacilaciones y de los presentimientos negativos que expresa en cartas, aforismos y poemas, decida, después de largas deliberaciones y de haber rehusado varias veces, aceptar la corona ante la delegación de México en los siguiente términos:

Ich nehme die verfassunggebende Macht an, die mir die Nation verliehen hat, deren Organ Sie, meine Herren, sind, werde sie aber nur solange behalten, als es nötig ist, um in Mexiko die normale Ordnung und gemäßigt liberale Institutionen einzurichten. Ich werde mich daher [...] beeilen, die Monarchie unter den Schutz von Versfassungsgesetzen zu stellen, sobald die Befriedung des Landes voll erreicht ist (Arrangoiz 1985, citado por Ratz 2007: 26) ${ }^{21}$.

La imagen que Maximiliano nos lega de México más allá de cuestiones puramente políticas hay que extraerla fundamentalmente de su correspondencia y de forma indirecta de los testimonios de aquellos que le acompañaron en su periplo, como es el caso de las memorias de su jardinero, Wilhelm Knechtel (s.d.), que dejan constancia de la pasión del emperador por la cultura prehispánica, por la arquitectura, la naturaleza y la jardinería.

La correspondencia privada con su esposa Carlota durante los años de reinado mexicano, accesible en abierto sólo desde 1975 y publicada por Konrad Ratz en el año 2000 bajo el sugerente título "Vor Sehnsucht nach dir vergehend” (una de las fórmulas de despedida de Maximiliano en las cartas a su esposa), nos muestra a un Maximiliano cuyos intereses son fundamentalmente políticos y hacen sombra, aunque no ocultan, al espíritu romántico que caracteriza sus memorias. En 2007, Konrad Ratz y Amparo Gómez Tepexicuapan publicaron un detallado análisis de los viajes del emperador por tierras mexicanas, que fueron cubiertos en todo detalle por los periódicos de la época como El pájaro Verde, El diario del Imperio, La Sociedad o las publicaciones locales de los lugares que visitaba (Ratz 2007: 41-43). Cinco son los viajes que se presentan en esta obra siendo el último un viaje sin retorno a Querétaro, que culminaría con su ejecución. También Ratz nos muestra

20 Parece demostrado que el decreto de la Asamblea de Notables mexicanos que ofreció el imperio a Maximiliano, así como las múltiples cartas de adhesión que éste había exigido para aceptar la corona fueron una farsa (FOSTER 1911: 190-192).

21 Arrangoiz, por su parte, considera "erróneo cuanto se ha dicho y escrito sobre las dudas y la desconfianza de Maximiliano" y afirma que "se encontraba en una situación tan anómala y desairada en Austria, en donde era mal visto de su propia familia por la ambición y las ideas liberales que [...] por salir de ella habría aceptado cualquier cosa, y con mucha más razón la corona de un país nuevo y rico como Méjico" (Arrangoiz 1869: 30). 
que estos viajes tienen un carácter eminentemente político: Maximiliano no quería conocer sólo el país y a sus gentes sino gobernar sobre el terreno.

El viaje a Brasil tiene un talante muy distinto al que reflejan las cartas a Carlota: el primero muestra un talante alegre, fresco, lleno de humor, que todavía delata al joven Habsburgo sin grandes preocupaciones, sin embargo, las cartas están escritas por un emperador que no puede congraciarse con el romántico soñador. La imagen que queda de México es la de un país de gentes alegres pero que han sido víctimas de un gobierno reaccionario demasiado conservador, anclado en la costumbre y alejado del pueblo. Una vez más se destaca el potencial de la región y se critica a las instituciones que impiden que ésta se desarrolle. Maximiliano transmite una imagen que se aleja de la que se tenía en Viena de ese país y de sus habitantes; sirva como ejemplo la obra de Charles Sealsfield, Der Virey und die Aristokraten oder Mexiko im Jahre 1812, que describe la lucha de los mexicanos contra España. Y aunque el autor muestra una evidente simpatía por los americanos, se propagan los viejos clichés negativos sobre los mismos: ladinos, taimados, cobardes y traidores. A los mexicanos les faltan los valores más sublimes como la religiosidad, las buenas costumbres y la moral (Altmann 1995: 486), lo que nos recuerda a las críticas que el propio Maximiliano realizó en Brasil.

\section{Conclusiones}

Maximiliano no pudo ver culminado su sueño, que en ocasiones se percibe como pesadilla, de construir un nuevo estado mediante reformas liberales que pudieran enmendar su déficit de legitimación por una serie de razones de política interior y exterior, que en su mayor parte eran predecibles (Ratz 2007: 34-36, 187). La imagen que nos lega de Latinoamérica es la de unos países con un enorme potencial, con una riqueza natural excepcional pero con incapacidad de gestionarse políticamente (como también percibiera en España) y de administrar los recursos naturales. Por un lado, admira y añora el alejamiento de la civilización europea, el naturalista es capaz de apreciar en todo su valor los recursos naturales vírgenes y el romántico su belleza incorrupta, pero su faceta política le impide no aplicar una perspectiva eurocéntrica a la forma de gobierno que podría salvar estos países del atraso con respecto a la cultura occidental. Maximiliano no consigue escapar a los estereotipos y sus descripciones con frecuencia muestran la condescendencia del conquistador, una proyección etnocéntrica en la que se admira su naturaleza paradisiaca a la vez que se desprecia la presunta barbarie de sus habitantes, lo que se corresponde con la percepción del continente americano que encontramos en Europa sobre todo en la primera mitad del siglo $\mathrm{XIX}^{22}$. Maximiliano, aunque decepcionado y crítico con la situación social y

22 Sirva como ejemplo la siguiente carta de Georg Weerth a Heinrich Heine escrita desde Angostura (Orinoco) en julio de 1853: "Vor aller Civilisation weit entfernt, kann ich Ihnen wenig erzählen, was von Interesse für Sie sein wird. [...] Man hat keine Idee davon, wie groß und wie schön die Welt eigentlich ist, wenn man nicht Meere und Länder durchstrichen hat. Und im Anschaun großer Naturgegenstände verliert man den Glauben an die Wichtigkeit einzelner Menschen und ganzer Völker.

Nichtsdestoweniger bleiben wir Europäer die Aristokraten des Erdkreises, und noch jahrhundertelang werden die plebeyischen Völker neuer Kontinente in den Staub niederknieen, um unsre weißen Hände zu küssen. Mögen alle Wälder des Orinoco rauschen, sie spielen noch keine Beethovensche Symphonie; mögen alle Geier 
política en Europa, no puede evitar un ansia civilizadora, aunque sin llegar a hablar de "misión civilizadora", como algunos críticos han denominado su relación con Latinoamérica, un anhelo que mira más al pasado que al presente, y son las reflexiones y referencias nostálgicas al pasado junto con su carácter mixto lo que convierte a estos relatos en documentos únicos.

El diario de su viaje a España está impregnado de una fantasía orientalista, está caracterizado por las proyecciones míticas románticas, por la mirada anhelante a la propia historia, así como por un desprecio por la Ilustración francesa. Maximiliano llega a España con una imagen predeterminada, la suya es una España dorada, pero ésta se irá afianzando a lo largo de su viaje. Sus bocetos tienen muchos elementos comunes con otros relatos de la época, de los que se diferencian básicamente por las contantes reflexiones y referencias al pasado añorado, en los que aúna una particular memoria con la historia. La relación que Maximiliano tiene con España es la que se tiene con los lugares de memoria, que adquieren significado en los ojos del observador como punto de encuentro con la historia, como forma de conectar el pasado con el presente. Maximiliano, sobre la fragilidad de una memoria manipulada, recrea una historia que en parte sólo existe en su imaginación, aunque para él se perciba como real. No hay que confundir memoria con historia, dijo Pierre Nora, aunque la historia, como reconstrucción, también sea manipulable y se apoye en la memoria, ésta es afectiva y mágica, sólo retiene los detalles que la refuerzan: "[das Gedächtnis] nährt sich von unscharfen, vermischten, globalen oder unsteten Erinnerungen, besonderen oder symbolischen, ist zu allen Übertragungen, Ausblendungen, Schnitten oder Projektionen fähig", se aferra a lo concreto, al espacio, al gesto, a la imagen y al objeto (Nora 1990: 13).

Cuando Maximiliano, que tenía más alma de artista que de gobernante y político, conoce los planes de Napoleón III de ofrecerle la corona de México, país que desde la Conquista en 1519 y hasta la declaración de Independencia de 1821 estuvo bajo virreinato español, aunque con un talante más liberal que diez años antes, considera posible hacer realidad el deseo que se gestó en su viaje a España y se afianzó en Brasil: devolver a la dinastía Habsburgo el esplendor perdido, aunque los ideales a los que se remitía no tuvieran más realidad que la del arte y la palabra.

\section{Referencias bibliográficas}

Altmann, W., «Entre barbarie y paraíso. La imagen de América Latina en la literatura alemana», Thesaurus L, 1-3 (1995), 478-491.

Boletín de las leyes del Imperio Mexicano, ó sea Código de la Restauración. Tomo I. México: Imprenta literaria 1863.

Arrangoiz, F., Apuntes para la historia del Segundo Imperio Mejicano. Madrid: Imprenta Rivadeneyra 1868.

Burian, P., «Maximilian, Kaiser von Mexiko», Neue Deutsche Biographie 16 (1990), 507511.

Canstatt, O., Brasilien Land und Leute. Hamburg: Severus 1912 [1877].

Corti, E. C. C., Maximiliano y Carlota. México: Fondo de Cultura Económica 1997. 
Elizondo, H., Personajes de Tragedia. Carlota y Maximiliano. México: Ed. Cultura 1956.

Ferdinand Maximilian, Erzherzog von Österreich, Reise-Skizzen. Spanien. Als Manuskript gedruckt. Viena: Kaiserl. Königl. Hof- und Staatsdruckerei 1855.

Foster, J. W., «Maximilian and His Mexican Empire», Records of the Columbia Historical Society 14 (1911), 184-204.

Galeana de Valadés, P., Las relaciones Iglesia-Estado durante el Segundo Imperio. México: UNAM 1991.

García-Wistädt, I., «Deutsche Reisende in Spanien in den Jahren von 1808 bis 1848: Ein Überblick», Estudios Filológicos Alemanes 18 (2009), 101-111.

García-Wistädt, I., «Krieg und Romantik. Vom Spanischen Unabhängigkeitskrieg bis zur deutschen Märzrevolution», en: Raposo Fernández, B. / Gutiérrez Koester, I. (eds.), Bis an den Rand Europas. Spanien in deutschen Reiseberichten vom Mittelalter bis zur Gegenwart. Frankfurt am Main: Vervuert 2011, 167-225.

García-Wistädt, I., «Interkulturelle Wahrnehmung oder Stereotypisierung? Das spanische Orientbild in den deutschen Reiseberichten der ersten Hälfte des 19. Jahrhunderts», en: Beníšková, B. (ed.), Interkulturalität in Sprache, Literatur und Bildung. Pardubice: Univerzita Pardubice 2012, 119-125.

Hamann, B., Mit Kaiser Max in Mexiko. Aus dem Tagebuch des Fürsten Carl Khevenhüller 1864-1867. Viena: Amalthea 1983.

Hamann, G., «Erzherzog Maximilian als Freund und Förderer der Geographie und Naturwissenschaft», en: Ruaro Loseri, L. (ed.), Massimiliano. Rilettura di un'esistenza. Atti del convegno, Trieste, 4-6 marzo 1987. Monfalcone: Edizioni della Laguna 1992, 120130.

Heine, H., Säkularausgabe. Werke. Briefwechsel. Lebenszeugnisse [HSA]. Band 27: Briefe an Heine 1852-1856. Berlín: Akademie Verlag 1976.

Herder, J. G., Sämtliche Werke. Zur schönen Literatur und Kunst. Siebenter Theil. Abhandlungen und Briefe. Karlsruhe 1821.

Jüttner, S., «Spanien - Land ohne Aufklärung? Zur Wiedergewinnung eines verdrängten Erbes», en: Jüttner, S. (ed.), Europäische Aufklärung(en). Einheit und nationale Vielfalt. Hamburg: Meiner 1992, 249-268.

Kahle, G., «Erzherzog Maximilians Projekt einer habsburgischen Doppelmonarchie in Amerika», en: Ruaro Loseri, L. (ed.), Massimiliano. Rilettura di un'esistenza. Atti del convegno, Trieste, 4-6 marzo 1987. Monfalcone: Edizioni della Laguna 1992, 88-100.

Knechtel, W., Handschriftliche Aufzeichnungen meiner persönlichen Eindrücke und Erlebnisse in Mexico in den Jahren 1864-1867. Praga: Selbstverl. s.d.

Maximilian, Kaiser von Mexiko, Aus meinem Leben. Reiseskizzen, Aphorismen, Gedichte. 7 vols. Leipzig: Duncker und Humblot 1867.

Maximiliano de Austria, Por tierras de España. Bocetos literarios de viajes (1851-1852). Edición de M. A. Vega y K. Rudolf. Madrid: Cátedra 1999.

MoMa.org (s.f.) Manet and the Execution of Maximilian. http://www.moma.org/interac tives/exhibitions/2006/Manet [12.11.2015].

Nora, P., Zwischen Geschichte und Gedächtnis. Berlín: Wagenbach 1990.

Ratz, K. / Gómez Tepexicuapan, A., Ein Kaiser unterwegs. Die Reisen Maximilians von Mexiko 1864-1867 nach Presseberichten und Privatbriefen. Viena: Böhlau 2007.

Ratz, K. (ed.), "Vor Sehnsucht nach vergehend”. Der private Briefwechsel zwischen Maximilian von Mexiko und seiner Frau Charlotte. Viena: Amalthea 2000.

Ratz, K., Maximiliano de Habsburgo. México: Planeta 2002.

Ratz, K., Tras las huellas de un desconocido. Nuevos datos y aspectos de Maximiliano de Habsburgo. México: Siglo XXI 2008.

Rudolf, K., «Los diarios de viaje españoles del archiduque Fernando Maximiliano de Austria (Maximiliano de Méjico) 1851-1852», en: Espinosa, J. / Casanova, E. (eds.), Homenatge a José Belloch Zimmermann. Valencia: Universitat de València 1988, 349-362. 
Said, E., Orientalismo. Madrid: Libertarias 1990.

Scholler, H., "Alexander von Humboldt und die Weltumsegelung der Novara»., Annalen des Naturhistorischen Museums in Wien 62 (1958), 5-24.

Springer, E., «Maximilians Persönlichkeit», en: Wandruszka, A. et al., Maximilian von Mexiko. 1832-1867 [Katalog zur Ausstellung auf Burg Hardegg]. Viena: Enzenhofer 1974, 12-23.

Wawra, H., Botanische Ergebnisse der Reise Seiner Majestät des Kaisers von Mexico Maximilian I. nach Brasilien (1859-1860). Viena: C. Gerold's Sohn 1866.

Wolfzettel, F., «Spanien als europäischer Orient und die (romantische) Andalusienreise: Edgar Quinets, "Mes vacances en Espagne" im Kontext», en: Wolfzettel, F. (ed), Reiseberichte und mythische Struktur: Romanistische Aufsätze 1983-2022. Stuttgart: Franz Steiner 2003, 246-248. 